\title{
Children's reactions to nonreward: Partial vs continuous reinforcement using a within-subjects design'
}

IRA J. SEMLER, UNIVERSITY OF IOWA DAVID R. PEDERSON, UNIVERSITY OF WESTERN ONTARIO

A within-Ss design was used in which each of 40 first grade children made 20 instrumental lever pulling responses to each of two stimuli $\left(S_{100}\right.$ and $\left.S_{50}\right)$. All responses associated with $S_{100}$ and $50 \%$ of the responses associated with $S_{50}$ were reinforced. Faster lever movement speeds were found on $S_{50}$ relative to $S_{100}$ trials. Implications of frustration theory for these results were contrasted with similar findings in studies using a between-Ss design.

The typical experiment on the effect of differential reinforcement on instrumental behavior in children has made between-Ss comparisons of groups of Ss under different reinforcement percentages. For example, Bruning (1964), Pederson (1967), Ryan (1965), and Ryan \& Moffitt (1966) have shown that instrumental lever pulling is faster for children under a 50\% reward condition than for children under a $100 \%$ reward condition.

Amsel et al (Amsel, Mackinnon, Rashotte, \& Surridge, 1964; Amsel \& Ward, 1965) have suggested that a within-Ss design has certain advantages over a between-Ss design in such studies. It should be noted that a within-Ss design would involve what is essentially a differential conditioning situation where one stimulus is associated with continuous reinforcement and a second stimulus is associated with partial reinforcement. This design provides statistical control over the wide individual differences in instrumental response speeds that inflate the between-groups error terms and reduce the apparent precision of between-Ss comparisons. Further, if the effect of reinforcement percentage differences could be demonstrated within-Ss, then similar procedures could be used to clarify the role of nonreward in discrimination learning, since in discrimination learning nonreward also occurs differentially to two stimuli.

In the present experiment, first grade children were instructed to depress a button and listen for a tone at the onset of either a red or a green warning light and then to pull a lever at the onset of a tone. For half of the Ss, a marble reward was given on $100 \%$ of the trials initiated by the red warning light and on $50 \%$ of the trials initiated by the green warning light. The reward contingencies were reversed for the remaining Ss in order to counterbalance conditions.

Methed

Forty first grade children enrolled in the Cedar Rapids Community School District, Iowa, served as Ss.
The CAs of these Ss ranged from 6-2 to 7-8 years, with a mean $\mathrm{CA}$ of 6-8 years.

The apparatus was a gray plywood box with a sloping front panel. A circular white button was located on the lower right front of the panel some $18 \mathrm{in.} \mathrm{from} \mathrm{the}$ handle of a spring return response lever which could be pulled downward through a $\mathbf{1 5}$ in. excursion channel. This channel was surrounded by a $1-1 / 2$ in. translucent plastic stimulus panel which could be backlighted with a series of elther red or green lamps. Each trial was initiated by illuminating the stimulus panel with either the red or the green lamps as a ready signal for $S$ to press the button, hold it down, and listen for a tone. A $600 \mathrm{~Hz}$ tone, signaling $\mathrm{S}$ to pull the response lever, was presented $3.5 \mathrm{sec}$ after $S$ pressed the button. Three Standard Electric Timers were used to obtain measures of the speed with which $S$ moved his hand from the button after the tone onset (initiation time), the speed of movement from the button to the lever handle (travel time), and the speed of the lever pulling (movement time). The $\mathrm{E}$ recorded the three time measures after each of 40 trials. On rewarded trials, a marble was dispensed into a box directly below the bottom of the excursion channel and in full view of $\mathrm{S}$. The Ss stored the marbles in a 100 hole marble board for later use as tokens in a device presenting colored View-Master slides. Each marble was worth 4.5 sec of viewing time.

Twenty Group 100-Red Ss received a marble on each trial initiated by the red ready signal but received a marble on only $50 \%$ of the trials initiated by the green ready signal. The reinforcement contingencies for the two colors were reversed for Group 100-Green to counterbalance conditions. It follows that each $S$ received continuous reinforcement for responses following a ready signal of one color $\left(S_{100}\right)$ and partial reinforcement for responses following a ready signal of the other color $\left(\mathrm{S}_{50}\right)$. A different random presentation sequence of $S_{100}$ and $S_{50}$ was used for each $S$ with the restriction that each color initiate four trials in each of five eight-trial blocks. For $\mathrm{S}_{50}, \mathrm{a}$ random sequence of two rewarded and two nonrewarded trials was established for each trial block.

The Ss were conducted individually to a semidarkened experimental room, allowed to select a set of colored slides and place them in the View-Master device, and given a marble to use as a token for $\mathbf{4 . 5}$ sec of slide viewing. The lever apparatus was then introduced as a machine for obtaining more marbles. 


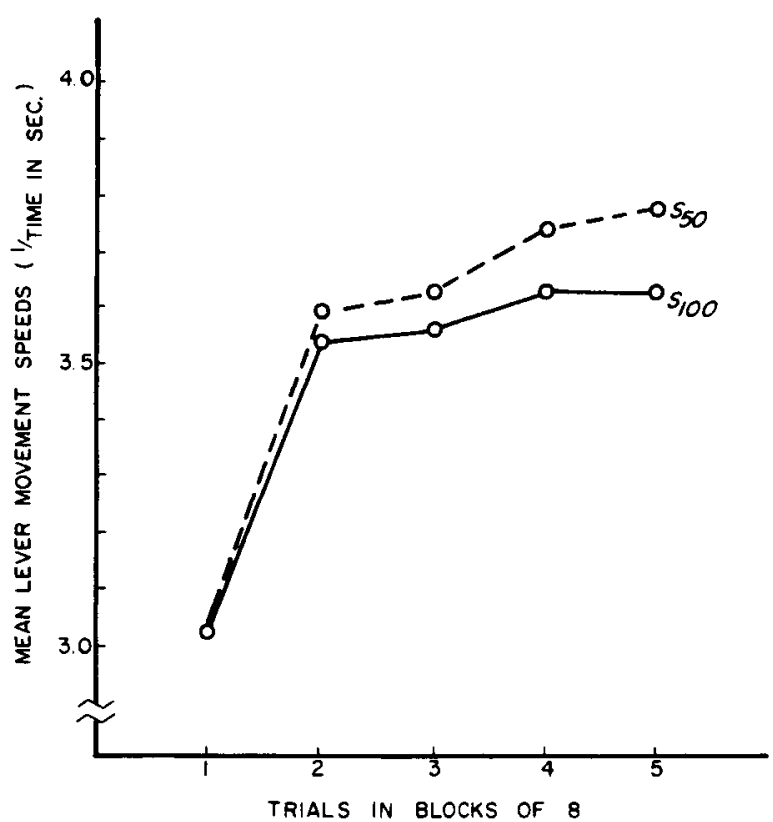

Fig. 1. Lever movement speed means for the $S_{50}$ and $S_{100}$ conditions averaged over $\mathrm{Ss}$ and counterbalancing conditions as a function of five blocks of eight trials.

The $\mathrm{S}$ was instructed to depress the white button when either the red or the green light was presented and that the tone onset was the signal to pull the lever. Resulis

Separate Lindquist (1953) higher-order analyses of variance were carried out on initiation speed, travel speed, and movement speed (reciprocals of the respective time scores). The between-Ss effect in each of these analyses was counterbalancing condition (Group 100-Red vs Group 100-Green); the within-Ss factors were reinforcement percentage (speeds on $S_{100}$ vs speeds on $\mathrm{S}_{50}$ trials) and trial blocks (five blocks of eight trials).

Figure 1 shows that lever movement speeds increased significantly across trial blocks ( $F=26.42$, df $=4 / 152$, $p<.05)$ with faster speeds under the $S_{50}$ than under the $S_{100}$ condition $(F=7.26, d f=1 / 38, p<.05)$. Counterbalancing conditions were not significant. Reinforcement percentage was not a significant factor in the analyses of initiation and travel speed scores.

\section{Discussion}

Finding faster lever movement speeds under partial than under continuous reinforcement in this experiment is consistent with the results of studies making similar comparisons between groups of Ss; however, quite different interpretations may be involved when the frustration hypothesis is applied in a comparative analysis of the within-Ss and the between-Ss procedures. Amsel (1965) and Spence (1960) have extended the concepts of conditioning theory to include frustrative-nonreward premises by assuming that: (a) the occurrence of nonreward when reward is anticipated leads to an "emotional" response, primary frustration, accompanied by a generalized drive increment; and (b) anticipatory frustration develops through the association of primary frustration with stimuli preceding nonreward. Anticipatory frustration presumably functions as a secondary source of drive (Brown, 1961). In between-Ss designs, faster response speeds under partial compared to continuous reinforcement could be attributed to a general increase in motivational level resulting from primary frustration or from anticipatory frustration elicited by environmental cues. In the present study, faster responding under $S_{50}$ could not be attributed to a general motivational increase since each $\mathrm{S}$ served as his own control. After several trials, anticipatory frustration may have been elicited by the onset of $\mathrm{S}_{50}$. The $3.5 \mathrm{sec}$ interval between the differential cue onset and the signal to respond was introduced to allow the hypothesized drive increment due to anticipatory frustration to occur. The performance differences in this study can be attributed to a higher motivational level on $S_{50}$ relative to $S_{100}$ trials and support the contention that anticipatory frustration can function as an acquired source of drive.

\section{References}

AMSEL, A., MACKINNON, J. R., RASHOTTE, M. E., \& SURRIDGE,

C. T. Partial reinforcement (acquisition) effects within subjects. $J$. exp. anal Behav., 1964, 7, 135-138.

AMSEL, A., \& WARD, J. S. Frustration and persistence: Resistance to discrimination following prior experience with the discriminanda. Psychol. Monogr., 1965, 79, No. 4 (Whole No. 597).

BROWN, J. S. The motivation of behavior. New York: McGraw-Hill, 1961.

BRUNING, J. L. The effects of magnitude of reward and percentage of reinforcement on a lever movement response. Child Develpm. 1964, $35,281-285$.

LINDQUIST, E. F. Design and analysis of experiments in psychology and education. Boston: Houghton Mifflin, 1953.

PEDERSON, D. R. Associative versus motivational interpretations of reward percentage effects on children's performance. Psychon. Sci, 1967, 8, 139-140.

RYAN, T. J. The effects of nonreinforcement and incentive value on response speed. Child Develpm., 1965, 36, 1067-1081.

RYAN, T. J., \& MOFFITT, A. R. Response speed as a function of age, Incentive value, and reinforcement schedule. Child Develpm., 1966, $37,103-114$.

SPENCE, K. W. Behavior theory and learning. Englewood Cliffs, New Jersey: Prentice-Hall, 1960.

Note

1. Portions of this paper were presented at the thirty-eighth annual meeting of the Midwestern Psychological Association, Chicago, May, 1966. 